\title{
10-Shogaol, an Antioxidant from Zingiber officinale for Skin Cell Proliferation and Migration Enhancer
}

\section{Chung-Yi Chen ${ }^{1}$, Kuo-Chen Cheng ${ }^{2,3,4}$, Andy Y Chang ${ }^{5,6}$, Ying-Ting Lin ${ }^{7}$, You-Cheng Hseu ${ }^{8}$ and Hui-Min Wang ${ }^{6, *}$}

1 Department of Medical Laboratory Science and Biotechnology, School of Medical and Health Sciences, Fooyin University, 151, Ching-Hsueh Road, Ta-Liao District, Kaohsiung 83102, Taiwan;

E-Mail: xx377@mail.fy.edu.tw

2 Department of Internal Medicine, Chi-Mei Medical Centre, Tainan 710, Taiwan;

E-Mail:kcg.cheng@gmail.com

3 Department of Safety Health and Environment, Chung Hwa University of Medical Technology, Tainan 717, Taiwan

4 Department of Medicine, National Defense Medical Center, Taipei 114, Taiwan

5 Department of Biology, University of California, Riverside, Riverside, CA 92521, USA

E-Mail: Chang.Andy.Y@gmail.com

6 Department of Fragrance and Cosmetic Science, Kaohsiung Medical University, 100, Shih-Chuan 1st Road, San-Ming District, Kaohsiung 80708, Taiwan

7 Department of Biotechnology, College of Life Sciences, Kaohsiung Medical University, Kaohsiung 80708, Taiwan; E-Mail: ytlin@kmu.edu.tw

8 Department of Cosmeceutics, College of Pharmacy, China Medical University, Taichung 404, Taiwan; E-Mail: ychseu@mail.cmu.edu.tw

* Author to whom correspondence should be addressed; E-Mail: davidw@kmu.edu.tw; Tel.:+886-7-312-1101-2804; Fax:+886-7-3210683.

Received: 22 December 2011; in revised form: 9 January 2012 / Accepted: 13 January 2012 / Published: 8 February 2012

Abstract: In this work, one of Zingiber officinale components, 10-shogaol, was tested with 1,1-diphenyl-2-picrylhydrazyl (DPPH) radical scavenging, metal chelating ability, and reducing power to show antioxidant activity. 10-Shogaol promoted human normal epidermal keratinocytes and dermal fibroblasts cell growths. 10-Shogaol enhanced growth factor production in transforming growth factor- $\beta$ (TGF- $\beta$ ), platelet derived growth 
factor- $\alpha \beta$ (PDGF- $\alpha \beta)$ and vascular endothelial growth factors (VEGF) of both cells. In the in vitro wound healing assay for 12 or $24 \mathrm{~h}$, with 10-shogaol, the fibroblasts and keratinocytes migrated more rapidly than the vehicle control group. Thus, this study substantiates the target compound, 10-shogaol, as an antioxidant for human skin cell growth and a migration enhancer with potential to be a novel wound repair agent.

Keywords: ginger; 10-shogaol; antioxidant activities; skin cell; proliferation; growth factors; migration

\begin{abstract}
Abbreviations: BHA: 3-tert-butyl-4-hydroxyanisole; DMEM: Dulbecco's modified Eagle's medium; DMSO: dimethyl sulfoxide; DPPH: 1,1-diphenyl-2-picrylhydrazyl; EDTA: ethylene diamine tetra-acetic acid; FBS: fetal bovine serum; PDGF- $\alpha \beta$ : platelet derived growth factor- $\alpha \beta ; \mathrm{K}_{3} \mathrm{Fe}(\mathrm{CN})_{6}$ : potassium ferricyanide; TGF- $\beta$ : transforming growth factor- $\beta$; VEGF: vascular endothelial growth factors
\end{abstract}

\title{
1. Introduction
}

Antioxidant applications are important for protecting the human body from various sources of oxidative damage and are used extensively for prevention of a variety of diseases. It has many bio-functions including anti-allergenic, anti-inflammatory, anti-bacterial and anti-viral activities, and the prevention of carcinogenesis, diabetes and heart disease [1-5]. Previous studies revealed that oxidative stress has deleterious effects on mesenchymal progenitor cells in terms of decreasing cell proliferation, increasing apoptosis and inhibiting their differentiation [6]. High concentration of free radicals within human body can induce oxidative stress and cellular damage by altering the biological activities of lipids, proteins, DNA and carbohydrates, even to cellular death [7]. In order to protect the human body from various forms of oxidative damage, recently there has been a noticeable increase in the search and identification of natural and safe antioxidants [8]. Dietary supplements and natural antioxidants, from beverages, cereals, fruits, and many vegetables, have gained popularity in recent years due to their abilities to enhance the body's antioxidant defenses [9]. To decelerate or prevent in vitro and in vivo oxidation reactions, antioxidants were used to terminate the oxidation chain reactions [10].

Among the many groups of growth factors, TGF- $\beta$ has been identified to be the most potent growth factor that is able to regulate cell migration, fibrotic scar formation, and wound closure. Furthermore, TGF- $\beta$ enhances cellular migratory movements, also known as scarring, and stimulates the proliferation of myofibroblast phenotype [11]. It is produced by fibroblasts, keratinocytes, macrophages and platelets. TGF- $\beta$, along with other growth factors in the same family, assists in cellular adhesion, differentiation, migration and proliferation. During wound healing procedures, TGF- $\beta$ is crucial in angiogenesis, connective tissue regeneration, inflammation and re-epithelialization [12]. PDGF- $\alpha \beta$ is essential in the proliferation of human skin cells. When the skin is wounded, traces of PDGF- $\alpha \beta$ 
secreted from related cells can be detected in wound fluid. VEGF is exemplified as the vascular permeability factor and is secreted by endothelial, fibroblasts, keratinocytes, macrophages, neutrophils, platelets and smooth muscle cells. VEGF is a vital regulator of endothelial cell migration, proliferation, and permeability in physiological and pathological angiogenesis [13]. In extracellular matrix (ECM) development, PDGF- $\alpha \beta$ and TGF- $\beta$ induce the permeation and the conversion of fibroblasts to myofibroblasts which creates the constrictive forces that helps the closure of the wound. PDGF- $\alpha \beta$ secretes TGF- $\beta$ by stimulating immune macrophages. PDGF- $\alpha \beta$ also cooperates synergistically with hypoxia ischemic damage tissues to increase the VEGF expression [14]. All the growth factors mentioned have interactions with each other during skin cell proliferations or wound healing processes.

Ginger, the powdered rhizomes of the herb Zingiber officinale Roscoe (Zingiberaceae), is a spice that is widely used in many types of cuisine. In traditional Chinese medicine, ginger, known to be a cure-all remedy, is used in treatments for ailments such as allergy, anti-microorganism infection, asthma, constipation, diabetes, gingivitis, nervous diseases, rheumatism, and stroke [15]. Shogaols are compounds formed by dehydrating gingerols, and also were not thought to be present in fresh rhizome (Figure 1). Typical proportions of 6-, 8- and 10-gingerol are 58\%, 22\% and 20\%, respectively. The ratios of 6-, 8- and 10-shogaols depends on the extent of the dehydration process and storage of gingerols [16,17]. 6-Shogaol was described to not only have anti-cancer and anti-inflammatory capabilities, but also had the potential to be used as an anti-metastatic treatment [18]. At pro-apoptotic concentrations, 10-shogaol, an extract from ginger, was able to induce $\mathrm{G}(2) / \mathrm{M}$ arrest and abnormal mitotic cell death that is associated with tubulin aggregation [19]. 10-Shogaol, the only non-pungent compound among the gingerols and shogaols, has the ability to stimulate the increase of adrenaline secretion [20]. Literature studies showed that the multiplication of free radicals in cells resulted in the suppression of cell viability, which implies that antioxidant exhibits relatively positive effects on cell proliferation. It was demonstrated that free radicals inhibit the proliferation and migration of vascular smooth muscle cells, both in vivo and in vitro, that contributes to vascular injury [21]. In this study, antioxidant activities were explored by employing various established in vitro systems. There were several in vitro and in vivo reports about the skin cell proliferation induced by curcumin and ginger extracts $[22,23]$. The goal of this study was to systematically evaluate 10 -shogaol's ability to enhance human normal skin cell growth. Furthermore, this was also the first attempt to demonstrate the bio-activites of 10-shogaol for medical cosmetology wound repair purposes.

Figure 1. The structure of ginger compound, 10-shogaol.

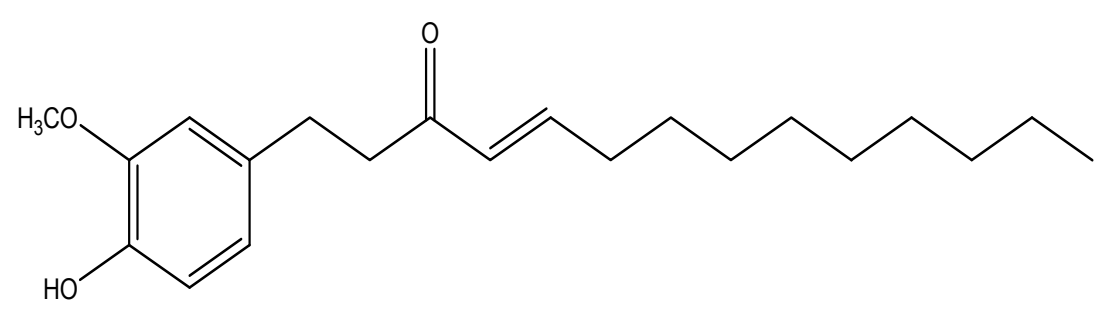




\section{Results and Discussion}

\subsection{Antioxidant Activities}

Antioxidants have singlet oxygen-quenching properties, free radical-scavenging abilities and transition metal-chelating capacities. Through the use of 1,1-diphenyl-2-picrylhydrazyl (DPPH) radical scavenging method, metal chelating ability test and reducing power assay antioxidant properties in ginger compound, 10-shogaol, was tested. The data is expressed as a mean value of three independent experiments with \pm standard deviation (SD). In DPPH free radical scavenging assay, 10-shogaol inhibits the oxidative products which allows it to form a stable complex (Table 1). In the assay, 10-shogaol reduced the stable radical DPPH to a yellow-colored diphenyl-picrylhydrazine. The results showed that 10 -shogaol has middle to high inhibitory effect $(34.54 \%)$ in comparison to vitamin $\mathrm{C}$ which has high inhibitory effect (92.02\%).

Table 1. Antioxidant effects of 10-shogaol.

\begin{tabular}{cccc}
\hline Samples & DPPH. Scavenging (\%) & Metal Chelating (\%) & $\begin{array}{c}\text { Reducing Power } \\
\left(\mathbf{1 0 0} \boldsymbol{\mu M}, \mathbf{O D}_{\mathbf{7 0 0}}\right)\end{array}$ \\
\hline $10-$ Shogaol & $34.54 \pm 0.02$ & $<10.00$ & $0.60 \pm 0.02$ \\
Vitamin C $^{\text {a }}$ & $90.02 \pm 0.40$ & - & - \\
EDTA $^{\text {b }}$ & - & $94.78 \pm 0.60$ & - \\
BHA $^{c}$ & - & - & $0.98 \pm 0.11$ \\
\hline${ }^{a}$ Vitamin C was used as a positive control on DPPH assay; ${ }^{b}$ EDTA was used as a positive control \\
on metal chelating ability at $100 \mu \mathrm{M} ;{ }^{c}$ BHA was used as a positive control on reducing power at \\
$100 \mu \mathrm{M}$, and so did testing samples; $-:$ no testing.
\end{tabular}

Ferrozine quantitatively formed complexes with $\mathrm{Fe}^{2+}$. With the existence of chelating agents, such as 10-shogaol, the complex becomes disrupted resulting in the appearance of a bright red color. The inhibition of 10 -shogaol was $<10.00 \%$ with a minor level of $\mathrm{Fe}^{2+}$ scavenging effect, whereas ethylene diamine tetra-acetic acid (EDTA) presented a strong scavenging ability with a $84.78 \%$ inhibition (Table 1 ).

In the reducing power assay, the color of the testing solutions changes from yellow to different shades between green and dark blue depending on the reducing power of the antioxidant. The presence of 10-shogaol is similar to the antioxidant substances in the antioxidant samples that induces the reduction of $\mathrm{Fe}^{3+} /$ ferricyanide complex to the ferrous form. As seen in Table 1, 10-shogaol is shown to have a moderate reducing power at $100 \mu \mathrm{M}\left(\mathrm{OD}_{700}=0.60\right)$ while 3-tert-butyl-4-hydroxyanisole (BHA) at the same dosage level $\left(\mathrm{OD}_{700}=0.94\right)$.

Antioxidants are molecules that decelerate and prevent the oxidation reaction in vitro and in vivo by terminating the oxidation chain reaction. Numerous crude extracts and pure natural compounds from plants are reported to have antioxidant and radical scavenging activities [10]. Over accumulation and formation of free radicals would accelerate the oxidation of lipids, found in cosmetics and foods with low quality, which will result in a reduced consumer acceptance [24]. Overall, 10-shogaol showed moderate antioxidant activities with the application in pharmacology to improve current treatments for diseases. 


\subsection{Cell Viabilities}

10-Shogaol was used on human skin cells to examine its effects on skin cell viability. [3-(4,5-Dimethylthiazol-2-yl)-2,5-diphenyltetrazolium bromide] (MTT) assay was performed to test if 10-shogaol has cytotoxic properties on keratinocytes (epidermal) and fibroblasts (dermal) (Figure 2). Various concentrations of 10-shogaol were added to both keratinocytes and fibroblasts, in order to observe their effect on cell proliferation. In keratinocytes, $2 \mu \mathrm{M}$ displayed the highest increase in cell viability (180.25\%) compared to the vehicle group. No significant difference was observed in concentration levels $50 \mu \mathrm{M}$. The cell viabilities gradually decreased in a dose-dependent manner from 2 to $100 \mu \mathrm{M}$. There was a discrepancy between this study and our previous ones, where ginger compounds were discovered for their anticancer properties in inhibiting cell growth and migration [25,26]. It is assumed that the dosages, treatment periods or cell types in the different experimental designs are the cause of the different cell growth.

Figure 2. Human keratinocytes and fibroblasts cell growths were treated with 10-shogaol at various concentrations for $24 \mathrm{~h}$ culture. The graph illustrates the mean $\pm \mathrm{SD}$ of three independent experiments. Bars: SD. ${ }^{*} p<0.05$ against the vehicle control group.

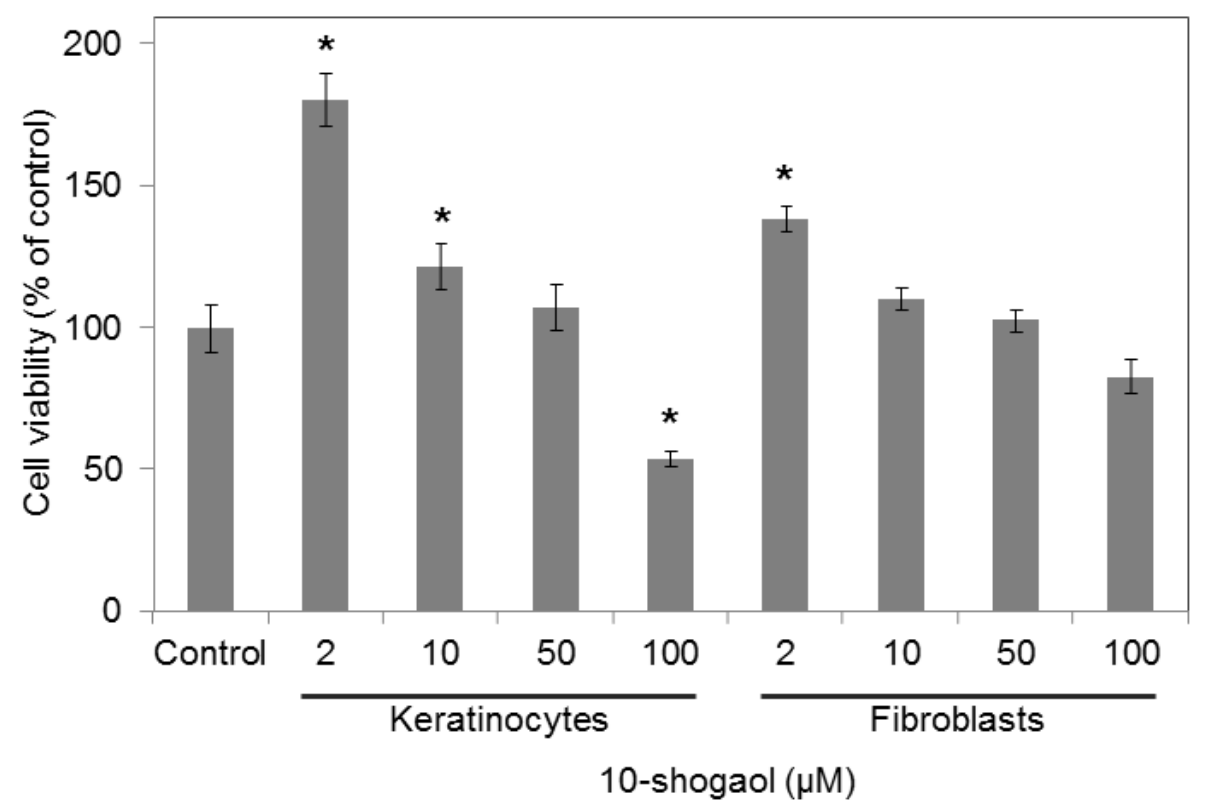

Similar to keratinocytes, fibroblasts also demonstrated a high increase in cell proliferation with the addition of $2 \mu \mathrm{M}$ of 10-shogaol (138.01\%). There was also no noticeable difference when 10 and $50 \mu \mathrm{M}$ of 10 -shogaol was added to fibroblast. 10-Shogaol, at low doses of $2 \mu \mathrm{M}$, has shown to have positive effects on cell viability along with increasing the rate of cell proliferation in both keratinocytes and fibroblasts. 


\subsection{Increasing Growth Factor Production (TGF- $\beta, P D G F-\alpha \beta$ and VEGF) of Human Fibroblasts and}

Keratinocytes by 10-Shogaol

TGF- $\beta$, PDGF- $\alpha \beta$ and VEGF, growth factors that are renowned cell proliferation enhancers have been chosen to be evaluated. As shown in Figure 3, the expression of growth factors was observed using enzyme linked immunosorbent assay (ELISA). To ensure that dimethyl sulfoxide (DMSO) does not affect the assays, DMSO is comprised of $1 \%$ of the comparing control. No significant difference was observed between assays with DMSO or without. The results showed that TGF- $\beta$ in keratinocytes increased from 665.4 to $834.2 \mathrm{pg} / \mathrm{mL}(125.37 \%)$ and $740.0 \mathrm{pg} / \mathrm{mL}(111.21 \%)$ after the incubation of 10 -shogaol at 2 and $10 \mu \mathrm{M}$ for $24 \mathrm{~h}$, respectively (Figure 3A). In fibroblasts, TGF- $\beta$ increased from 778.3 to $909.5 \mathrm{pg} / \mathrm{mL}(116.9 \%)$ and $878.3 \mathrm{pg} / \mathrm{mL}(112.9 \%)$ after we incubated the compound at 2 and $10 \mu \mathrm{M}$ for $24 \mathrm{~h}$, respectively as shown in Figure 3B. For PDGF- $\alpha \beta$ in keratinocytes, the concentration content varied obviously. 10-Shogaol treatments at $2 \mu \mathrm{M}$ showed the greatest increase in concentration values $(2.20$ to $4.97 \mathrm{pg} / \mathrm{mL}, 225.9 \%)$, followed by 10 -shogaol treatments at $10 \mu \mathrm{M}(2.20$ to $4.31 \mathrm{pg} / \mathrm{mL}, 195.9 \%$ ) in Figure 3C. In Figure 3D, 10-shogaol treatments at $2 \mu \mathrm{M}$ also presented the greatest increase in concentration values $(2.50$ to $5.32 \mathrm{pg} / \mathrm{ml}, 212.8 \%$ ), followed by 10 -shogaol treatments at $10 \mu \mathrm{M}(2.5$ to $3.55 \mathrm{pg} / \mathrm{mL}, 142.0 \%)$ of fibroblasts. For VEGF in keratinocytes, 10 -shogaol treatments at $2 \mu \mathrm{M}$ demonstrated the increase in concentration values $(250.7$ to $325.5 \mathrm{pg} / \mathrm{mL}$, $129.8 \%$ ), followed by 10 -shogaol treatments at $10 \mu \mathrm{M}(250.7$ to $314.5 \mathrm{pg} / \mathrm{mL}, 125.4 \%)$ in Figure $3 \mathrm{E}$. In fibroblasts, 10 -shogaol treatments at $2 \mu \mathrm{M}$ showed an increase of $108.8 \%$ (287.1 to $312.3 \mathrm{pg} / \mathrm{mL})$. 10-Shogaol treatments at $10 \mu \mathrm{M}$ illustrated no considerable difference when compared to the vehicle group (Figure 3F).

Figure 3. Three growth factors secretive productions effected by 10-shogaol on human skin keratinocytes $(\mathbf{A}, \mathbf{C}, \mathbf{E})$ and fibroblasts $(\mathbf{B}, \mathbf{D}, \mathbf{F})$. The data was shown as mean \pm SD of three independent experiments. Significance for three different time-point groups was accepted at $* p<0.05$ or $* * p<0.01$ versus their corresponding controls.

(A)

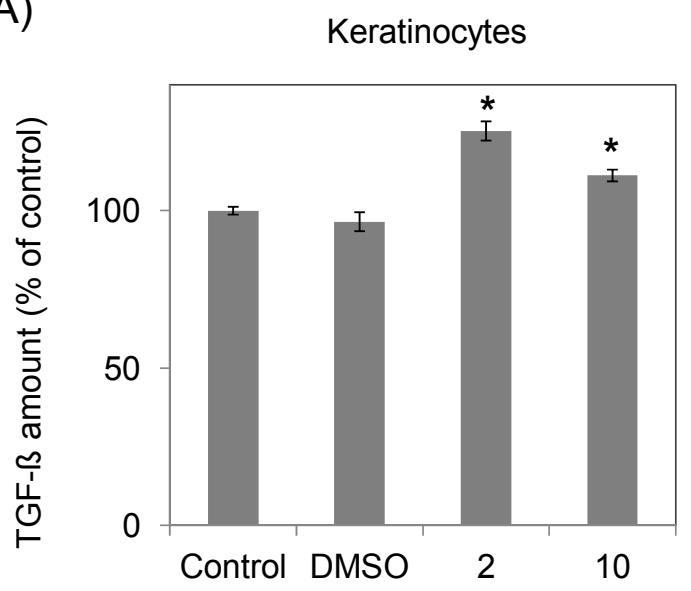

(B)

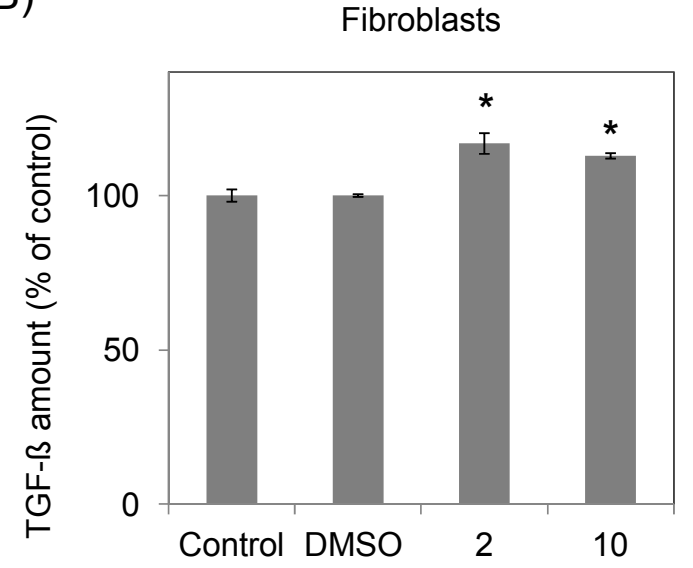


Figure 3. Cont.

(C)

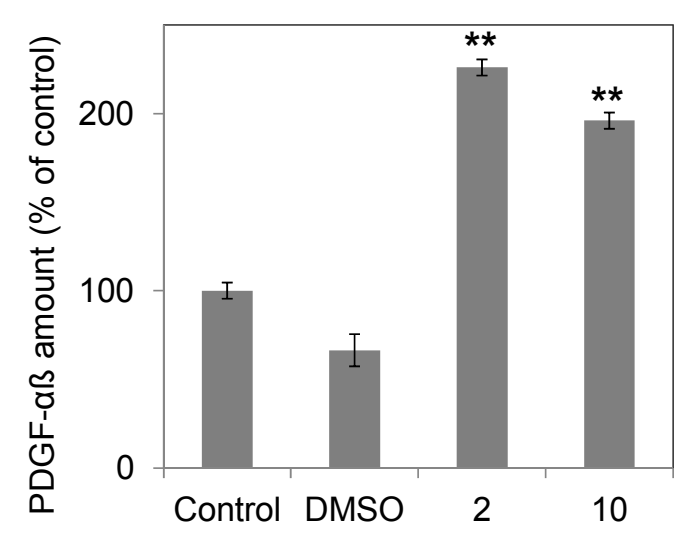

(E)

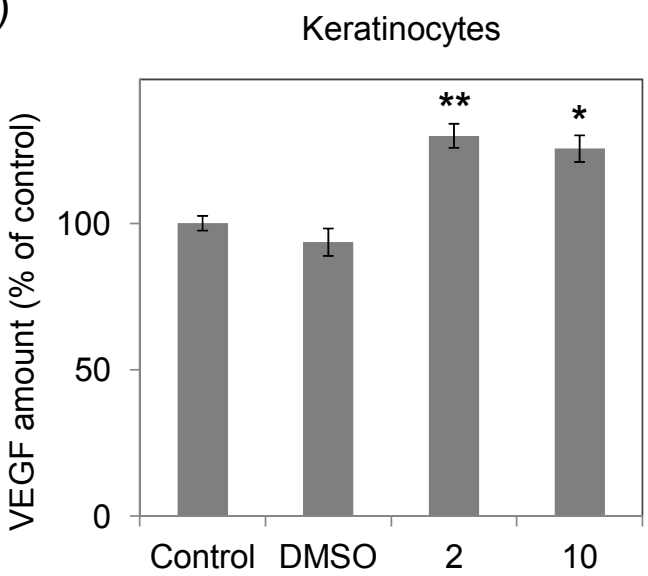

(D)

Fibroblasts

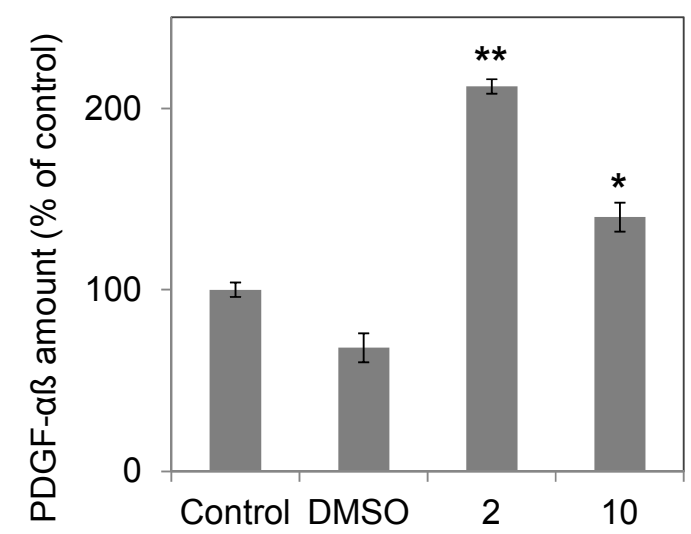

(F)

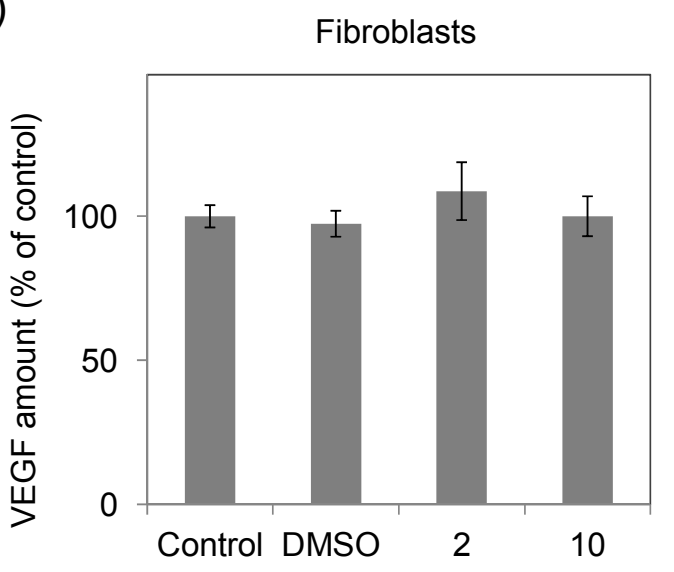

The formation of granulation by TGF- $\beta$ provides the protection to the healthy tissues that surrounds the wounded area. TGF- $\beta$, with the separation of de-granulating platelets at the wound site, has an impact on the angiogenesis, ECM deposition, inflammatory response, re-epithelialization, and remodeling [27]. With the addition of 10-shogaol, both keratinocytes and fibroblasts' TGF- $\beta$ concentration rose significantly in comparison with the vehicle group. TGF- $\beta$ level was slightly higher in keratinocytes than in fibroblast (Figure 3A,B). PDGF- $\alpha \beta$ is generated expressed and secreted by fibroblasts, keratinocytes, macrophages, platelets and vascular endothelium. By recruiting pericytes and strengthening its structural foundation, PDGF- $\alpha \beta$, during wound repairing, plays a predominant role in blood vessels development [28]. When treated with 10-shogaol, PDGF- $\alpha \beta$ concentration level was noticeably higher in keratinocytes than in fibroblasts in Figure 3C,D. 10-Shogaol was able to increase the PDGF- $\alpha \beta$ and TGF- $\beta$ concentration allowing it to have skin injury repair applications. In wound healing, VEGF, a remarkable growth factor, expedites skin injury repair by stimulating angiogenesis, cell proliferations and migrations [29]. VEGF assists in the organization and synthesis of ECM, which is essential to the restoration of ECM near the wounded tissue zone. After the treatment with 10-shogaol, there were visible increases of VEGF concentrations in keratinocytes and fibroblasts in Figure 3E,F. The increase in keratinocytes was especially significant. In our assumptions, the VEGF 
production was not up-regulated by the 10-shogaol in fibroblasts. As stated in the introduction, upon injury, the stimulation of immune macrophages by PDGF- $\alpha \beta$ triggers immune macrophages to secrete TGF- $\beta$, which also aids in the rise of VEGF expression. We advocated that the increase of TGF- $\beta$, PDGF- $\alpha \beta$ and VEGF regulatory secretions might be due to the addition of 10-shogaol.

\subsection{Cell Migrations of Fibroblasts and Keratinocytes Enhanced by 10-Shogaol}

To determine the effects of 10 -shogaol on keratinocytes and fibroblasts migration, an in vitro wound healing assay was performed (Figure 4). The keratinocytes and fibroblasts migration rates were based on the efficiency of monolayer cells invading the wound region with the 10-shogaol treatments at 2 and $10 \mu \mathrm{M}$ in 12 and $24 \mathrm{~h}$ testing periods. Keratinocytes and fibroblasts were individually cultured to monolayer confluence on an uncoated 6-well culture dish followed by applying a scratch with a sterile pipette tip. After extensive washing with PBS, cells were treated with either vehicle or varying concentrations of 10-shogaol for the indicated time periods. The photos of cell repairing enhancing effects of 10-shogaol on keratinocytes migrations can be observed in Figure 4A. Quantification analysis of the increasing abilities of 10-shogaol in treatment conditions are shown in Figure 4B. Keratinocytes exhibited an increase in cell migration with the addition of 10 -shogaol. At $2 \mu \mathrm{M}$, the cell migration exhibited a greater migration rate at $24 \mathrm{~h}(236.0 \%)$ than at $12 \mathrm{~h}(204.76 \%)$. At $10 \mu \mathrm{M}$, the cell migration displayed a higher migration rate at $24 \mathrm{~h}(250.44 \%)$ than at $12 \mathrm{~h}(205.65 \%)$. The treatments of 10-shogaol in fibroblasts also showed the rise in cell migrations. When treated with $2 \mu \mathrm{M}$, the cell migration was $201.67 \%$ at $12 \mathrm{~h}$ and $246.06 \%$ at $24 \mathrm{~h}$. When cured with $10 \mu \mathrm{M}$, the cell migration was $187.82 \%$ at $12 \mathrm{~h}$ and $237.92 \%$ at $24 \mathrm{~h}$.

Figure 4. In vitro wound healing assay on 10-shogaol effects on human skin cells. (A) Migratory photographs of human keratinocytes; (B) Quantification of the migration potential of 10-shogaol- or PBS-treated cells; (C) Photographs of fibroblasts; (D) Fibroblasts migration quantifications. The data was shown as mean $\pm \mathrm{SD}$ of three independent experiments. Significance for three different time-point groups was accepted at $* p<0.05$ versus their corresponding controls.

(A)

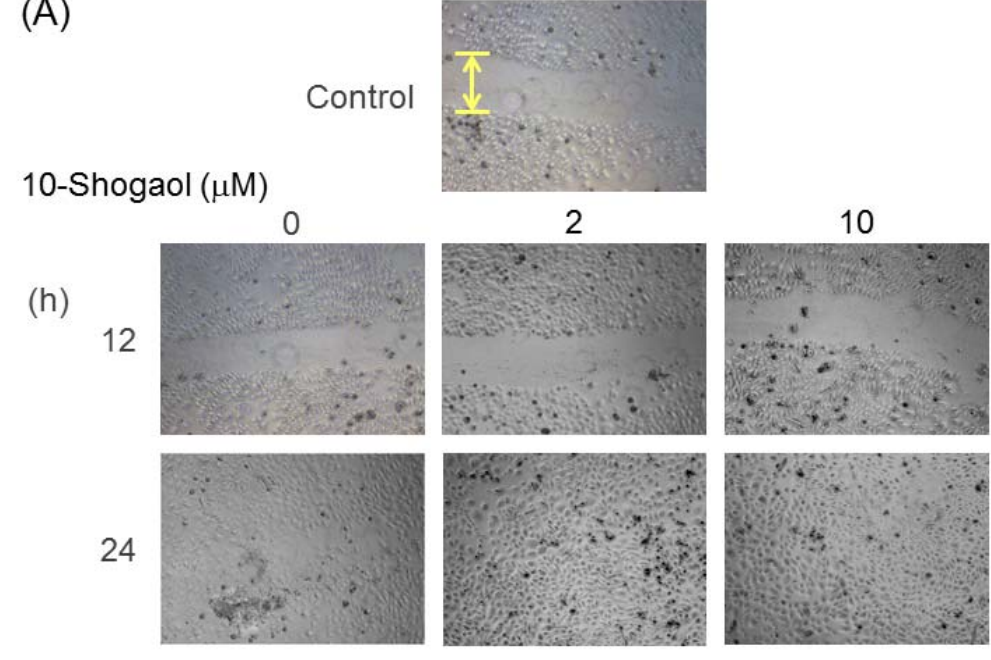


Figure 4. Cont.

(B)

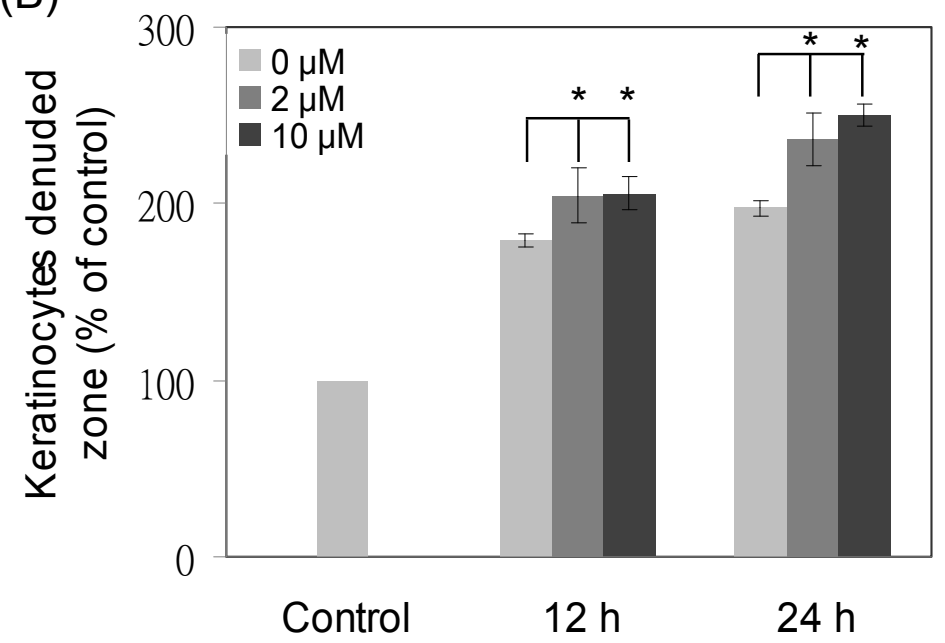

(C)

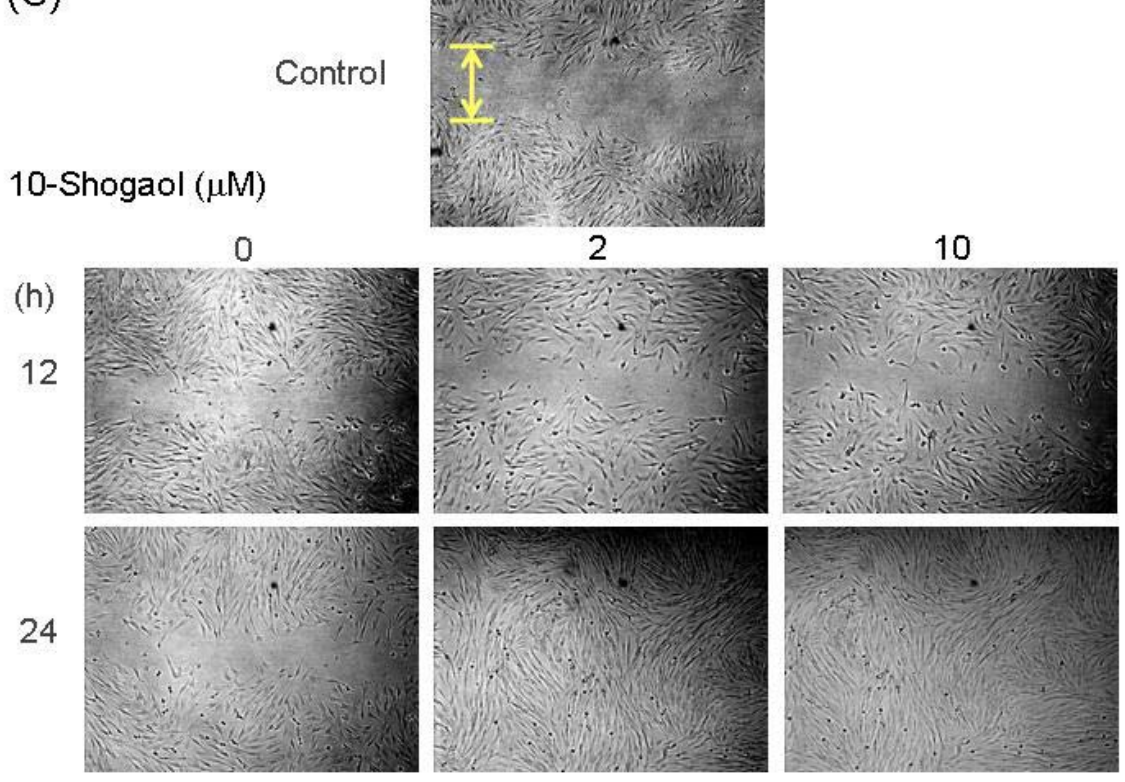

(D)

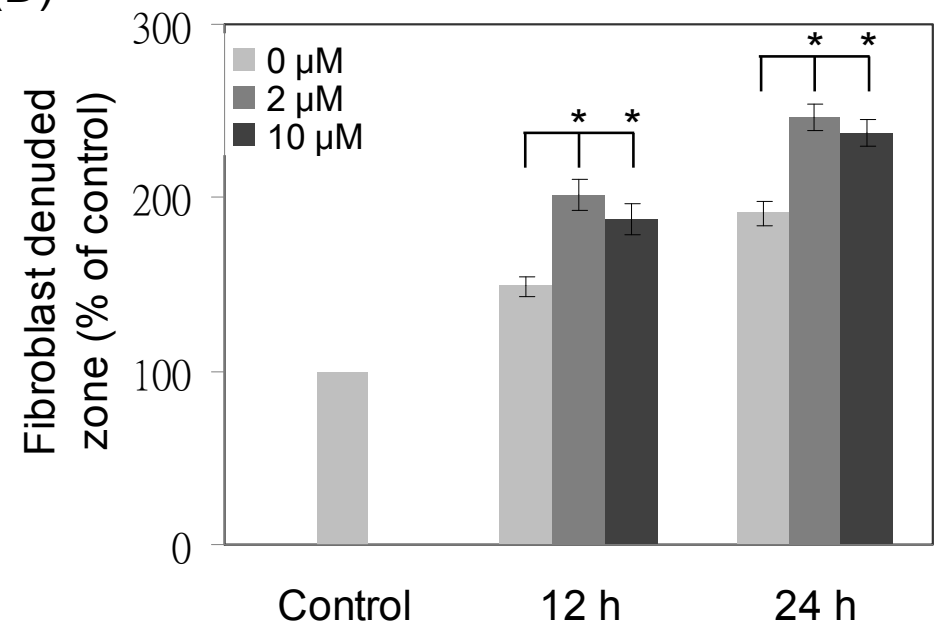


Ginger compounds have the ability to induce faster abrasion wound repair by decreasing reactive oxygen species or modulating collagen [30]. The assay system that was used to test the effects of 10-shogaol on keratinocytes and fibroblasts migration abilities was cultured from normal human skin cells. Skin wound healing was slower as opposed to those that were treated with ginger compounds, which induced the skin to repair much more efficiently [23]. In the in vitro wound repairing assay, 10-shogaol treated-cells migrated to the clearing area at a faster pace and rate than the control group. When treated with our target compound for $24 \mathrm{~h}$, the wound region was almost completely covered by keratinocytes and fibroblast migratory cells.

In the $12 \mathrm{~h} \mathrm{10-shogaol}(2 \mu \mathrm{M})$ treatment of keratinocytes, the pre-wound region appeared narrower than the vehicle control which had a larger gap. After $24 \mathrm{~h}$, the treated wound area was completely closed and fully proliferated as opposed to the control which still had a gap. On the other hand, at $10 \mu \mathrm{M}$ treatment of 10 -shogaol on keratinocytes, the wound space seemed to be nearly closed while the control's opening appears the same as when it started. At $24 \mathrm{~h}$, the treated area was entirely closed unlike the control which still had some openings. When fibroblasts was treated with 10 -shogaol $(2 \mu \mathrm{M})$ for $12 \mathrm{~h}$, the injured region appeared to be thinner and the cell proliferation rate seemed to increase while the controlled region had no visible changes. At $24 \mathrm{~h}$, the wound area, treated with 10-shogaol $(2 \mu \mathrm{M})$, was fully closed unlike the control which still had a gap. When fibroblasts were treated with 10-shogaol $(10 \mu \mathrm{M})$ for $12 \mathrm{~h}$, the injured area appeared to be closing and the cells were migrating toward the middle. At $24 \mathrm{~h}$, the treated wound region was completely repaired while the control was healing at a slower rate. In this section, it is noticeable that 10-shogaol induced the expression of three growth factors which stimulated the migration and proliferation of keratinocytes and fibroblasts. In this study, it was suggested that 10 -shogaol enhanced skin cell growth and migration.

\section{Experimental Section}

\subsection{Materials}

DMSO, DPPH, vitamin C, EDTA, BHA, potassium ferricyanide $\left[\mathrm{K}_{3} \mathrm{Fe}(\mathrm{CN})_{6}\right]$, trichloroacetic acid, $\mathrm{FeCl}_{3}, \mathrm{FeCl}_{2} \cdot 4 \mathrm{H}_{2} \mathrm{O}$, MTT, penicillin, streptomycin, and amphotericin $\mathrm{B}$ were purchased from Sigma-Aldrich (St. Louis, MO, USA). Fetal bovine serum (FBS) and Dulbecco's modified Eagle's medium (DMEM) was obtained from GIBCO BRL (Gaithersburg, MD, USA). All other chemical buffers and reagents were purchased at the highest commercial purity and quality possible.

\subsection{Plant Materials}

Dried and chipped rhizomes $(25.6 \mathrm{~kg})$ of $Z$. officinale were extracted repeatedly with different mixtures of chloroform $(50 \mathrm{~L} \times 4)$ at room temperature, based on previous reports [31]. The combined chloroform extracts $(896.5 \mathrm{~g})$ were then evaporated further and separated into 20 fractions by column chromatography (CC) in the silica gel (3.8 kg, 70-230 mesh) with gradients of $n$-hexane/ $\mathrm{CHCl}_{3}$. Fr. 9 (121.2 g), eluted with $\mathrm{CHCl}_{3}-\mathrm{MeOH}(50: 1)$, was next subjected to silica gel $\mathrm{CC}\left(\mathrm{CHCl}_{3}-\mathrm{MeOH}\right.$ mixtures) and yielded 10-shogaol (210 mg). Fr. 10 (86.9 g), eluted with $\mathrm{CHCl}_{3}-\mathrm{MeOH}$ (50:1), was 
next repeatedly subjected to silica gel $\mathrm{CC}\left(\mathrm{CHCl}_{3}-\mathrm{MeOH}\right.$ mixtures) and yielded 6-shogaol (328 $\left.\mathrm{mg}\right)$. The extraction yielded pure 10-shogaol from different fractions by silica gel column chromatography with gradients of $n$-hexane/ $\mathrm{CHCl}_{3}$ (Figure 1). Using spectroscopy, the compound was analyzed and identified, and compared with literature values [32]. The purity of 10 -shogaol was $>95 \%$ as determined by HPLC. The chemical structure of 10-shogaol was confirmed by NMR [32].

\subsection{Determination of DPPH Radical Scavenging Capacity}

The antioxidant activity of the target compound, 10-shogaol, was measured in terms of hydrogen donating or radical scavenging ability using the modified DPPH method [33]. Different concentrations of the samples were added to $0.2 \mathrm{~mL}$ of a DPPH $(60 \mu \mathrm{M})$ solution. When DPPH reacts with an antioxidant compound that donates hydrogen, it is reduced resulting in a decrease in the absorbance at $520 \mathrm{~nm}$. The absorbance was recorded at 5 min intervals for 30 min using a UV visible spectrophotometer and was evaluated at the end point (30 min). Vitamin $\mathrm{C}$ was used as a positive control. The percentages of remaining DPPH were plotted against the sample to obtain the amount of antioxidant required to reduce the initial concentration of DPPH. Scavenging activity (\%) was determined with the following equation:

$$
100 \times\left(O D_{\text {control }}-O D_{\text {sample }}\right) / O D_{\text {control }}
$$

\subsection{Metal Chelating Activity}

The ferrous ion chelating potential of chlorophyll was investigated according to a previously described method [33]. Briefly, various testing concentrations of samples dissolved in DMSO were added to a solution of $2 \mathrm{mM} \mathrm{FeCl}_{2} \cdot 4 \mathrm{H}_{2} \mathrm{O}(0.05 \mathrm{~mL})$. The reaction was initiated by the addition of $5 \mathrm{mM}$ ferrozine $(0.2 \mathrm{~mL})$, and the mixture was vigorously shaken and left standing at room temperature for $10 \mathrm{~min}$. The absorbance of the mixture was then read at $560 \mathrm{~nm}$ against a blank. EDTA was used as a positive control, and the formula for calculation of the chelating activity was similar to Equation (1).

\subsection{Reducing Power Assay}

The reducing power of 10-shogaol was determined according to a previously described method [33]. Various concentrations of testing samples in $0.063 \mathrm{~mL}$ of methyl alcohol were mixed with $0.1 \mathrm{~mL}$ of $0.2 \mathrm{M}$ sodium phosphate buffer $(\mathrm{pH} 6.8)$ and $2.5 \mu \mathrm{L}$ of $20 \%$ potassium ferricyanide $\left(\mathrm{K}_{3} \mathrm{Fe}(\mathrm{CN})_{6}\right)$. The mixture was incubated at $50{ }^{\circ} \mathrm{C}$ for $20 \mathrm{~min}$, and $0.16 \mathrm{~mL}$ of trichloroacetic acid $(10 \%)$ was added to the mixture that was then centrifuged for $10 \mathrm{~min}$ at $3000 \mathrm{~g}$. The upper layer of the solution $(75 \mu \mathrm{L})$ was mixed with distilled water $(25 \mu \mathrm{L})$ and $2 \% \mathrm{FeCl}_{3}(25 \mu \mathrm{L})$, and the absorbance was measured with a 96-well plate spectrophotometer at $650 \mathrm{~nm}$. BHA was used as a positive control. A higher absorbance demonstrates a higher reductive capability. 


\subsection{Human Dermal Fibroblasts and Epidermal Keratinocytes Cultures}

Both human skin cell culture procedures followed the process of [34]. Briefly, the primary cultures of human skin fibroblasts, derived from Chung-Ho Memorial Hospital, Kaohsiung Medical University, Taiwan, ROC (KMUH-IRB-990269); were incubated in Eagle's medium (DMEM) with 10\% fetal calf serum, $100 \mu \mathrm{g} / \mathrm{mL}$ penicillin, $100 \mu \mathrm{g} / \mathrm{mL}$ streptomycin, and $250 \mathrm{ng} / \mathrm{mL}$ amphotericin B. Human keratinocytes were isolated from foreskin primary culture and cultured in Keratinocyte-SFM (10724; GIBCO ${ }^{\mathrm{TM}}$ ), supplemented with Bovine Pituitary Extract (BPE, cat. \# 13028-014), and EGF (cat. \# 10450-013). The medium and growth supplements for keratinocytes contain $\gamma$-epidermal growth factor, BPE, insulin, fibroblast growth factor and calcium $(0.09 \mathrm{mM})$. All cell types were incubated at $37{ }^{\circ} \mathrm{C}$ in a humidified incubator $5 \% \mathrm{CO}_{2}$ atmosphere.

\subsection{Cell Growth Assay}

The MTT assay was used to measure cell growth to test the compound used in this study could induce cell proliferation [35]. Briefly, skin cells were seeded in 96-well plates and treated with different concentrations of ginger compound or untreated (as positive control) for $24 \mathrm{~h}$. Stock MTT solution $(5 \mathrm{mg} / \mathrm{mL}$, dissolved in phosphate buffered saline, PBS) was diluted 1:10 in culture medium and added to a culture dish, then incubated at $37{ }^{\circ} \mathrm{C}$ for $2 \mathrm{~h}$. At the end of the incubation period, the medium was removed and replaced with $0.05 \mathrm{~mL}$ DMSO to dissolve the formazan crystals. The culture dishes were gently shaken for $20 \mathrm{~min}$ in the dark and added to a 96-well plate reading at $595 \mathrm{~nm}$ on a multiwall scanning spectrophotometer (UV-vis, BioTek, USA). The cell growth was calculated by the percentage of the control OD $(595 \mathrm{~nm})$ value (UV-vis, BioTek, USA). In consideration of the possible antiproliferative effects of DMSO, cultures were added with maximal $1 \%$ DMSO and used as positive controls, which was not found to affect skin cell growth.

\subsection{ELISA Assays}

We performed ELISA to determine the amounts of TGF- $\beta$, VEGF, and PDGF produced in skin cells after being exposed to the testing compound. The skin cells were cultured in 6-well plates under conditioned medium and the supernatant was collected at $24 \mathrm{~h}$ for analysis. Amounts of TGF- $\beta$, VEGF and PDGF- $\alpha \beta$ secreted in the culture medium were determined from DuoSet ELISA development kits (R \& D Systems, USA). The assay was performed according to the manufacturer's instructions, and protein amounts were measured and given as pictogram per milliliter with standard deviations (SD) of data derived from duplicate measurements.

\subsection{In Vitro Wound Healing Assay}

The potential of cellular migration was determined by wound healing migration assays, which was performed according to the methods reported by [3,35]. In brief, $5 \times 10^{5}$ cells were cultured in 12 -well plates, and grown to complete confluence. A yellow $200 \mu \mathrm{L}$ plastic pipette tip was used to create a clean 1-mm-wide wound area on a confluent culture of skin cells and washed three times to remove 
floating cells. Then, it was added with either vehicle (medium containing 0.5\% DMSO) or various concentrations of testing samples for the indicated time periods. After the indicated incubation time, the wound gaps were photographed using an inverted phase-contrast microscopy (TE2000-U; Nikon, Tokyo, Japan) equipped with NIS-Elements (Nikon) Software. The migration and cell movement throughout the wound area were examined and calculated by the free software "TScratch" (www.cse-lab.ethz.ch/software.html) [36]. Magnification: 100× Bars, SD.

\subsection{Statistical Analysis}

All data values are presented as the mean values $( \pm \mathrm{SD})$ of at least three independent experiments. Where appropriate, data were analyzed by the Student's $t$ test.

\section{Conclusions}

We identified one compound from Z. officinale, 10-shogaol, which has the ability to promote normal human skin cell growth (epidermal keratinocytes and dermal fibroblasts). In the cell viability tests, cell proliferation capabilities decreased from low to high dose concentration and the cell growth was greatest at $2 \mu \mathrm{M}$. In the in vitro wound healing assay, 10-shogaol, at $12 \mathrm{~h}$ and $24 \mathrm{~h}$, enhanced fibroblasts and keratinocytes migration. 10-Shogaol-treated fibroblasts and keratinocytes showed higher growth factor productions in transforming growth factor- $\beta$ (TGF- $\beta$ ), platelet derived growth factor- $\alpha \beta$ (PDGF- $\alpha \beta$ ) and vascular endothelial growth factors (VEGF). Thus, this work provided the molecular basis of 10-shogaol as a novel potential wound repairing agent.

\section{Acknowledgements}

The authors thank Chi-Peng Wu for her assistance and also express their gratitude to Cyndi Huang for the English editing. This work was financially supported by the National Science Council of the Republic of China under Grants NSC-99-2221-E-037-006-MY3 and NSC-97-2320-B-242-002-MY3 as well as the 2011 Taiwan Tech Trek Program (Andy Y Chang), and the Academic Community about Industry Program PS099150247.

\section{References}

1. Chen, B.H.; Chang, H.W.; Huang, H.M.; Chong, I.W.; Chen, J.S.; Chen, C.Y.; Wang, H.M. (-)-Anonaine induces oxidative stress and DNA damage to inhibit growth and migration of human lung carcinoma H1299 cells. J. Agric. Food Chem. 2011, 59, 2284-2290.

2. Wang, H.M.; Chou, Y.T.; Hong, Z.L.; Chen, H.A.; Chang, Y.C.; Yang, W.L.; Chang, H.C.; Mai, C.T.; Chen, C.Y. Bioconstituents from stems of Synsepalum dulcificum Daniell (Sapotaceae) inhibit human melanoma proliferation, reduce mushroom tyrosinase activity and to be antioxidants. J. Taiwan Inst. Chem. Eng. 2011, 42, 204-211. 
3. Wang, H.M.; Pan, J.L.; Chiu, C.C.; Chen, C.Y.; Yang, M.H.; Chang, J.S. Identification of anti-lung cancer extract from Chlorella vulgaris $\mathrm{C}-\mathrm{C}$ by antioxidant property using supercritical carbon dioxide extraction. Process Biochem. 2010, 45, 1865-1872.

4. Wang, H.M.; Chen, C.Y.; Chen, H.A.; Huang, W.C.; Lin, W.R.; Chen, T.C.; Lin, C.Y.; Chien, H.S.; Lu, P.L.; Lin, C.M.; Chen, Y.H. Zingiber officinale (ginger) compounds with tetracycline have synergistic effects against clinical extensively-drug resistant Acinetobacter baumannii. Phytother. Res. 2010, 24, 1825-1830.

5. Chen, B.H.; Wu, P.Y.; Chen, K.M.; Fu, T.Z.; Wang, H.M.; Chen, C.Y. Antiallergic potential on RBL-2H3 cells of some phenolic constituents of Zingiber officinale (Ginger). J. Nat. Prod. 2009, 72, 950-953.

6. Waddington, R.J.; Alraies, A.; Colombo, J.S.; Sloan, A.J.; Okazaki, J.; Moseley, R. Characterization of oxidative stress status during diabetic bone healing. Cells Tissues Organs 2011, 194, 307-312.

7. Mladenović, M.; Mihailović, M.; Bogojević, D.; Matić, S.; Nićiforović, N.; Mihailović, V.; Vuković, N.; Sukdolak, S.; Solujić, S. In vitro antioxidant activity of selected 4-hydroxy-chromene-2-one derivatives-SAR, QSAR and DFT studies. Int. J. Mol. Sci. 2011, 12, 2822-2841.

8. Zhang, H.; Wang, Z.Y.; Yang, L.; Yang, X.; Wang, X.; Zhang, Z. In vitro antioxidant activities of sulfated derivatives of polysaccharides extracted from Auricularia auricular. Int. J. Mol. Sci. 2011, 12, 3288-3302.

9. Fu, L.; Xu, B.T.; Gan, R.Y.; Zhang, Y.; Xu, X.R.; Xia, E.Q.; Li, H.B. Total phenolic contents and antioxidant capacities of herbal and tea infusions. Int. J. Mol. Sci. 2011, 12, 2112-2124.

10. Wei, S.D.; Zhou, H.C.; Lin, Y.M. Antioxidant activities of extract and fractions from the hypocotyls of the mangrove plant Kandelia candel. Int. J. Mol. Sci. 2010, 11, 4080-4093.

11. Amjad, S.B.; Carachi, R.; Edward, M. Keratinocyte regulation of TGF-beta and connective tissue growth factor expression: A role in suppression of scar tissue formation. Wound Repair Regen. 2007, 15, 748-755.

12. Rolfe, K.J.; Richardson, J.; Vigor, C.; Irvine, L.M.; Grobbelaar, A.O.; Linge, C. A role for TGF- $\beta 1$-induced cellular responses during wound healing of the non-scarring early human fetus? J. Invest. Dermatol. 2007, 127, 2656-2667.

13. Trompezinski, S.; Berthier-Vergnes, O.; Denis, A.; Schmitt, D.; Viac, J. Comparative expression of vascular endothelial growth factor family members, VEGF-B, -C and -D, by normal human keratinocytes and fibroblasts. Exp. Dermatol. 2004, 13, 98-105.

14. Stavri, G.T.; Hong, Y.; Zachary, I.C.; Breier, G.; Baskerville, P.A.; Yla-Herttuala, S.; Risau, W.; Martin, J.F.; Erusalimsky, J.D. Hypoxia and platelet-derived growth factor-BB synergistically upregulate the expression of vascular endothelial growth factor in vascular smooth muscle cells. FEBS Lett. 1995, 358, 311-315.

15. Afzal, M.; Al-Hadidi, D.; Menon, M.; Pesek, J.; Dhami, M.S. Ginger: An ethnomedical, chemical and pharmacological review. Drug Metabol. Drug Interact. 2001, 18, 159-190. 
16. Wohlmuth, H.; Smith, M.K.; Brooks, L.O.; Myers, S.P.; Leach, D.N. Essential oil composition of diploid and tetraploid clones of ginger (Zingiber officinale Roscoe) grown in Australia. J. Agric. Food Chem. 2006, 54, 1414-1419.

17. Shao, X.; Lv, L.; Parks, T.; Wu, H.; Ho, C.T.; Sang, S. Quantitative analysis of ginger components in commercial products using liquid chromatography with electrochemical array detection. J. Agric. Food Chem. 2010, 58, 12608-12614.

18. Ling, H.; Yang, H.; Tan, S.H.; Chui, W.K.; Chew, E.H. 6-Shogaol, an active constituent of ginger, inhibits breast cancer cell invasion by reducing matrix metalloproteinase- 9 expression via blockade of nuclear factor- $\kappa$ B activation. Br. J. Pharmacol. 2010, 161, 1763-1777.

19. Gan, F.F.; Nagle, A.A.; Ang, X.; Ho, O.H.; Tan, S.H.; Yang, H.; Chui, W.K.; Chew, E.H. Shogaols at proapoptotic concentrations induce $\mathrm{G}_{2} / \mathrm{M}$ arrest and aberrant mitotic cell death associated with tubulin aggregation. Apoptosis 2011, 16, 856-867.

20. Iwasaki, Y.; Morita, A.; Iwasawa, T.; Kobata, K.; Sekiwa, Y.; Morimitsu, Y.; Kubota, K.; Watanabe, T. A nonpungent component of steamed ginger-[10]-shogaol-increases adrenaline secretion via the activation of TRPV1. Nutr. Neurosci. 2006, 9, 169-178.

21. Wu, L.; Wang, G.; Tang, S.; Long, G.; Yin, T. Protection of endothelial cells, inhibition of neointimal hyperplasia by $\beta$-elemene in an injured artery. Cardiovasc. Drugs Ther. 2011, 25, 233-242.

22. Panchatcharam, M.; Miriyala, S.; Gayathri, V.S.; Suguna, L. Curcumin improves wound healing by modulating collagen and decreasing reactive oxygen species. Mol. Cell Biochem. 2006, 290, 87-96.

23. Bhagavathula, N.; Warner, R.L.; DaSilva, M.; McClintock, S.D.; Barron, A.; Aslam, M.N.; Johnson, K.J.; Varani, J. A combination of curcumin and ginger extract improves abrasion wound healing in corticosteroid-impaired hairless rat skin. Wound Repair Regen. 2009, 17, 360-366.

24. Yoshimura, K.; Tsukamoto, K.; Okazaki, M.; Virador, V.M.; Lei, T.C.; Suzuki, Y.; Uchida, G.; Kitano, Y.; Harii, K. Effects of all-trans retinoic acid on melanogenesis in pigmented skin equivalents and monolayer culture of melanocytes. J. Dermatol. Sci. 2001, Suppl. 1, S68-S75.

25. Chen, C.Y.; Tai, C.J.; Cheng, J.T.; Zheng, J.J.; Chen, Y.Z.; Liu, T.Z.; Yiin, S.J.; Chern, C.L. 6-Dehydrogingerdione sensitizes human hepatoblastoma Hep G2 cells to TRAIL-induced apoptosis via reactive oxygen species-mediated increase of DR5. J. Agric. Food Chem. 2010, 58, 5604-5611.

26. Hsu, Y.L.; Chen, C.Y.; Hou, M.F.; Tsai, E.M.; Jong, Y.J.; Hung, C.H.; Kuo, P.L. 6-Dehydrogingerdione, an active constituent of dietary ginger, induces cell cycle arrest and apoptosis through reactive oxygen species/c-Jun $N$-terminal kinase pathways in human breast cancer cells. Mol. Nutr. Food Res. 2010, 54, 1307-1317.

27. Riedel, K.; Riedel, F.; Goessler, U.R.; Germann, G.; Sauerbier, M. TGF- $\beta$ antisense therapy increases angiogenic potential in human keratinocytes in vitro. Arch. Med. Res. 2007, 38, 45-51.

28. Lindahl, P.; Johansson, B.R.; Leveen, P.; Betsholtz, C. Pericyte loss and microaneurysm formation in PDGF-B-deficient mice. Science 1997, 277, 242-245. 
29. Gerber, H.P.; Dixit, V.; Ferrara, N. Vascular endothelial growth factor induces expression of the antiapoptotic proteins Bcl-2 and A1 in vascular endothelial cells. J. Biol. Chem. 1998, 273, 13313-13316.

30. Panchatcharam, M.; Miriyala, S.; Gayathri, V.S.; Suguna, L. Curcumin improves wound healing by modulating collagen and decreasing reactive oxygen species. Mol. Cell Biochem. 2006, 290, 87-96.

31. Lin, R.J.; Chen, C.Y.; Lee, J.D.; Lu, C.M.; Chung, L.Y.; Yen, C.M. Larvicidal constituents of Zingiber officinale (Ginger) against Anisakis simplex. Planta Med. 2010, 76, 1852-1858.

32. Shoji, N.; Iwasa, A.; Takemoto, T.; Ishida, Y.; Ohizumi, Y. Cardiotonic principles of ginger (Zingiber officinale Roscoe). Pharm. Sci. 1982, 71, 1174-1175.

33. Wang, H.M.; Chen, C.Y.; Chen, C.Y.; Ho, M.L.; Chou, Y.T.; Chang, H.C.; Lee, C.H.; Wang, C.Z.; $\mathrm{Chu}$, I.M. (-)- $N$-Formylanonaine from Michelia alba as human tyrosinase inhibitor and antioxidant. Bioorg. Med. Chem. 2010, 18, 5241-5247.

34. Wang, H.M.; Chen, C.Y.; Wen, Z.H. Identifying melanogenesis inhibitors from Cinnamomum subavenium with in vitro and in vivo screening systems by targeting the human tyrosinase. Exp. Dermatol. 2011, 20, 242-248.

35. Wang, H.M.; Chiu, C.C.; Wu, P.F.; Chen, C.Y. Subamolide E from Cinnamomum subavenium induces sub G1 cell cycle arrest, caspase-dependent apoptosis, and reduces migration ability of human melanoma cells. J. Agric. Food Chem. 2011, 59, 8187-8192.

36. Geback, T.; Schulz, M.M.; Koumoutsakos, P.; Detmar, M. TScratch: a novel and simple software tool for automated analysis of monolayer wound healing assays. Biotechniques 2009, 46, $265-274$.

(C) 2012 by the authors; licensee MDPI, Basel, Switzerland. This article is an open access article distributed under the terms and conditions of the Creative Commons Attribution license (http://creativecommons.org/licenses/by/3.0/). 